\title{
Fractionation and Enzymatic Characterization of Endoprotease and Exopeptidase from Crude Extracts of Cuttlefish Sepia officinalis Hepatopancreas
}

\author{
Min Ji Kim ${ }^{1}$, Hyeon Jeong Kim ${ }^{1}$, Ki Hyun Kim ${ }^{1}$, Min Soo Heu ${ }^{2}$, Jung Suck Lee ${ }^{3}$ and Jin-Soo Kim ${ }^{1 *}$ \\ ${ }^{1}$ Department of Seafood Science and Technology, Gyeongsang National University, \\ Tongyeong 650-160, Korea \\ ${ }^{2}$ Department of Food Science Nutrition, Gyeongsang National University, Jinju 660-701, Korea \\ ${ }^{3}$ Industry-Academic Cooperation Foundation, Jeju National University, Jeju 690-756, Korea
}

\begin{abstract}
This study examines the optimal fractionation method and conditions for the isolation of endoprotease- and exopeptidase-active fractions from crude extracts of cuttlefish hepatopancreas (HP) using four fractionation methods: ammonium sulfate fractionation (ASF), polyethylene glycol fractionation (PGF), ion exchange chromatography (IEC), and gel filtration chromatography (GFC). Total endoprotease activity highest in the fraction II (concentrate of fractions 34-42; $842.60 \mathrm{U}$ ) of GFC, followed by fraction III (40-60\% ammonium sulfate fraction; $670.25 \mathrm{U}$ ) of ASF, fraction I (concentrate of fractions 8-12; 436.89 U) of IEC, and fraction II (10-20\% polyethylene glycol; $307.31 \mathrm{U})$ of PGF. Total exopeptidase activity of these fractions was highest in fraction II (2,704.70 $\mathrm{U})$ of GFC, fraction III (2,110.50 U) of ASF, fraction III (1,605.60 U) of PGF, and fraction II (concentrate of fractions 38-44; 1,196.22 U) of IEC. These results showed that fraction II of GFC had the highest activity toward both exopeptidase and endoprotease, with exopeptidase activity being 3.21 times higher than of endoprotease. These results suggest cuttlefish HP could be used as a potential source for the extraction of exopeptidase, an enzyme capable of catalyzing the cleavage of $\mathrm{N}$ - and $\mathrm{C}$-terminal amino acids in polypeptides, Like endoprotease, the most efficient method for separating exopeptide-active fractions was GFC.
\end{abstract}

Key words: Cuttlefish, Sepia officinalis, Hepatopancreas, Exopeptidase, Endoprotease

\section{Introduction}

A large quantity of cuttlefish has been caught in the adjoining Korea seas. In South Korea, the cuttlefish is a popular seafood, with an output of 4,109 metric tons in 2010 (Agriculture and Fishery Statistics Department, 2010). The cuttlefish processing industry generates large amounts of solid byproducts, including viscera, skin, and bone, which can cause major environment issues (Souissi et al., 2008). Among these solid by-products, viscera represents $14-16 \%$ of the original material and constitutes an important source of protein, lipids, and enzymes. Thus, using this by-product to act as a source for the extraction of important enzymes, such as endoprotease and exopeptidase, would be advantageous.

Proteases constitute the most important group of industrial enzymes used in the world today and account for $\sim 50 \%$ of the total industrial enzyme market (Rao et al., 1998; Bougatef et al., 2007). These enzymes have diverse applications in a wide variety of industries, including the detergent, food, agrochemical, and pharmaceutical industries (Gupta et al., 2002; Bougatef et al., 2007). In the food industry, proteases are most extensively used for improving the quality, stability, and solu-
Open Access http://dx.doi.org/10.5657/FAS.2012.0283

This is an Open Access article distributed under the terms of the Creative Commons Attribution Non-Commercial License (http://creativecommons. org/licenses/by-nc/3.0/) which permits unrestricted non-commercial use, distribution, and reproduction in any medium, provided the original work is properly cited. pISSN: 2234-1749 eISSN: 2234-1757
Received 30 October 2012; Revised 13 November 2012 Accepted 13 November 2012

*Corresponding Author

E-mail: jinsukim@gnu.ac.kr 
bility of foods produced by the baking, brewing, and cheesemaking processes, as well as meat processing (Haard, 1990; Heu et al., 2003). However, the enzymatic hydrolysates of various proteins frequently exhibit a bitter taste caused by bitter peptides, which limits their utilization in the food industry (Matoba et al., 1970; Clegg et al., 1974; Bumberger and Belitz, 1993; Izawa et al., 1997). Since bitterness is closely correlated with the hydrophobicity of the peptides (Clegg et al., 1974; Izawa et al., 1997), several attempts have been made to reduce the bitterness by hydrolyzing bitter peptides with exopeptidases (Minagawa et al., 1989; Umetsu et al., 2003). A1though many industrial proteases have been developed, a limited number of these commercial peptidases exist, including aminopeptidase and carboxypeptidase (Deejing et al., 2005).

The efficient isolation of endoprotease and exopeptidase from cuttlefish hepatopancreas (HP), requires the application of extraction, fractionation, and purification procedures. Among these procedures, fractionation is expected to significantly affect enzyme activity. In recent years, several studies have reported methods for the efficient extraction of hydrolysates (Kechaou et al., 2009), collagen and gelatin (Nagai et al., 2001; Aewsiri et al., 2009; Hoque et al., 2010), functional lipids (Park et al., 2011), media (Souissi et al., 2008), and calcium (Ivankovic et al., 2009) from cuttlefish-processing by-products, such as skin, viscera, and bone. However, an efficient method for the extraction of exopeptides, such as aminopeptidase and carboxypeptidase, has yet to be reported.

Here, we report the enzymatic characterization endoprotease- and exopeptidase-active cuttlefish HP fractions isolated by various separation methods, including ammonium sulfate fractionation (ASF), polyethylene glycol fractionation (PGF), ion exchange chromatography (IEC), and gel filtration chromatography (GFC).

\section{Materials and Methods}

\section{Materials}

Frozen cuttlefish Sepia officinalis HP was obtained from a traditional market in Tongyeong, Korea, in December 2010.

\section{Chemicals}

Endoprotease- and exopeptidase-active fractions were isolated using ammonium sulfate and polyethylene glycol purchased from Katayama Chemical Co. (Osaka, Japan) and Yacuri Pure Chemical Co. Ltd. (Kyoto, Japan), respectively. DEAE 650M and Sephacryl S300 were purchased from Tosoh Co. Ltd. (Tokyo, Japan) and Pharmacia (Uppsala, Sweden), respectively. L-leucine-p-nitroanilide (LeuPNA) and azocasein were purchased from Sigma-Aldrich Chemical Co. (St. Louis, MO, USA). All other chemicals used in these experiments were of analytical grade. The buffer solution $(0.1 \mathrm{M}$ sodium phosphate, $\mathrm{pH}$ 6) used to assess enzyme activity was prepared as previously described (Dawson et al., 1986).

\section{Preparation of the crude extracts (CE)}

Neocoleoidea CE was prepared by partially thawing frozen cuttlefish before homogenizing the HP with 3 volumes $(\mathrm{v} / \mathrm{w})$ of deionized water. Enzyme activation was performed by incubating the homogenates for $4 \mathrm{~h}$ at $20^{\circ} \mathrm{C}$, while stirring every $30 \mathrm{~min}$, and centrifuging the solutions at $12,000 \mathrm{~g}$ for $30 \mathrm{~min}$ at $4^{\circ} \mathrm{C}$. Finally, CE was obtained by treating the supernatant with 0.2 volumes of carbon tetrachloride and centrifuging the solution at $12,000 \mathrm{~g}$ for $30 \mathrm{~min}$ at $4^{\circ} \mathrm{C}$ to remove lipids.

\section{Protein concentration}

The protein concentration of the CE was measured as previously described (Lowry et al., 1951) using bovine serum albumin as a standard protein.

\section{Activity of endoprotease and exopeptidase}

Endoprotease activity was assessed using an azocasein as the substrate by a method described by Starky (1977) with some modifications. The CE $(100 \mu \mathrm{L})$ was mixed with 300 $\mu \mathrm{L}$ of $1 \%$ azocasein in $1.6 \mathrm{~mL}$ of $0.1 \mathrm{M}$ sodium phosphate ( $\mathrm{pH}$ 6.0) prior to incubation at $40^{\circ} \mathrm{C}$ for $1 \mathrm{~h}$. The reaction was stopped by the addition of $2 \mathrm{~mL}$ of $5 \%$ trichloroacetic acid solution, and the mixture was set before centrifuging at $146 \mathrm{~g}$ for $15 \mathrm{~min}$. The absorbance of the supernatant was recorded at $410 \mathrm{~nm}$ and expressed as endoprotease activity.

LeuPNA was used to assess exopeptidase activity using the method reported by García-Carreño and Haard (1993) with slight modification. Briefly, CE $(100 \mu \mathrm{L})$ were mixed with $100 \mu \mathrm{L}$ of LeuPNA in $2 \mathrm{~mL}$ of $0.1 \mathrm{M}$ sodium phosphate buffer $(\mathrm{pH} 6.0)$ and incubated at $40^{\circ} \mathrm{C}$ for $1 \mathrm{~h}$. The reaction was stopped by the addition of $0.3 \mathrm{~mL}$ of $33 \%$ acetic acid solution and allowed to set before centrifuging at $146 \mathrm{~g}$ for $15 \mathrm{~min}$. The absorbance of the supernatant was read at $410 \mathrm{~nm}$. One unit of activity was defined as the amount of enzyme required to increase the absorbance by 0.1 unit per min. Specific activity $(\mathrm{U} / \mathrm{mg})$ was defined as the activity unit per $\mathrm{mg}$ of protein.

\section{Fractionation of endoprotease and exopeptidase}

The CE were fractionated by ASF, PGF, IEC or GFC to obtain endoprotease- and exopeptidase-active fractions from cuttlefish HP.

\section{ASF fractionation of the CE}

The CE were fractionated by adding ammonium sulfate to the solutions in the range of $0-20 \%, 20-40 \%, 40-60 \%$, and 60 $80 \%$ saturation. These fractions were collected by centrifugation $\left(12,000 \mathrm{~g}\right.$, for $30 \mathrm{~min}$ at $\left.5^{\circ} \mathrm{C}\right)$ and dissolved in a minimum 
quantity of cold deionized water before dialyzing the solution in deionized water for $24 \mathrm{~h}$ at $5^{\circ} \mathrm{C}$. The dialyzed solutions were centrifuged at $12,000 \mathrm{~g}$, for $24 \mathrm{~h}$ at $5^{\circ} \mathrm{C}$ and the supernatants were stored at $-25^{\circ} \mathrm{C}$ until use.

\section{PGF fractionation of the CE}

The CE was fractionated by adding polyethylene glycol to the extract in the range of $0-5 \%, 5-10 \%, 10-20 \%$ and 20 $40 \%$. Fractions were collected by centrifugation $(12,000 \mathrm{~g}$, for $30 \mathrm{~min}$ at $5^{\circ} \mathrm{C}$ ) and dissolved in a minimum quantity of cold deionized water before dialyzing the solutions in deionized water for $24 \mathrm{~h}$ at $5^{\circ} \mathrm{C}$. Dialysates were centrifuged at 12,000 $g$, for $24 \mathrm{~h}$ at $5^{\circ} \mathrm{C}$, and the supernatants were stored at $-25^{\circ} \mathrm{C}$ until use.

\section{IEC fractionation of the CE}

A Toyopearl DEAE $650 \mathrm{M}$ column $(1.6 \times 20 \mathrm{~cm})$ was equilibrated with $10 \mathrm{mM}$ sodium phosphate buffer $(\mathrm{pH}$ 7.0) and washed with the same buffer until the conductivity of the eluent equaled that of the buffer. For isolation of the exopeptidase-active fraction, the CE were applied to the column and eluted before the addition of $110 \mathrm{~mL}$ of solution containing an increasing $\mathrm{NaCl}$ gradient $(0 \mathrm{M}, 0.5 \mathrm{M}$ and $1.0 \mathrm{M})$ at a flow rate of $30 \mathrm{~mL} / \mathrm{h}$. Protein content and protease activity were measured by monitoring absorbance at $280 \mathrm{~nm}$ and $410 \mathrm{~nm}$, respectively. Exopeptidase-active fractions ( $4 \mathrm{~mL} /$ tube) were collected and centrifuged at 3,000 rpm for $30 \mathrm{~min}$ using an Amicon Bioseparations Centriplus centrifugal filter devices (Millipore, Billerica, MA, USA) to concentration and dialyze the fraction. The supernatants were stored at $-25^{\circ} \mathrm{C}$ until enzymatic characterization.

\section{GFC fractionation of the CE}

A Sephadex S-300 column $(11.6 \times 20 \mathrm{~cm})$ was equilibrated with $10 \mathrm{mM}$ sodium phosphate buffer $(\mathrm{pH} \mathrm{7.0)}$ and washed with the same buffer until the conductivity of the eluent and the buffer was equal. Isolation of the exopeptidase-active fraction was accomplished by applying the column and eluting prior to separation at a flow rate of $12 \mathrm{~mL} / \mathrm{h}$. Protein content and protease activity were measured by reading the absorbances at 280 $\mathrm{nm}$ and $410 \mathrm{~nm}$, respectively. Exopeptidase-active fractions (4 mL/tube) were collected and centrifuged at 3,000 rpm for 30 min using an Amicon Bioseparations Centriplus centrifugal filter devices (Millipore), which concentrated and dialyzed the solution. The supernatants were stored at $-25^{\circ} \mathrm{C}$ until use.

\section{Results and Discussion}

This study focused on the efficient isolation of endoprotease- and exopeptidase-active fractions from cuttlefish HP using various fractionation methods, including ASF, PGF, IEC and GFC.

\section{Protease activity ASF fractions}

To identify the optimal ASF condition for isolating endoprotease- and exopeptidase-active fractions from cuttlefish $\mathrm{HP}$, the CEs were fractionated with increasing concentration of ammonium sulfate. The fractions were designated as fraction I (0-20\% ammonium sulfate), II (20-40\% ammonium sulfate), III (40-60\% ammonium sulfate) and IV (60-80\% ammonium sulfate).

Table 1 shows endoprotease and exopeptidase activities, as well as the fractional yield obtained from the CE of cuttlefish HP using various concentrations of ammonium sulfate. Specific activity and endoprotease-specific activities were highest in fraction II (2.86 U/mg and 1.4-fold, respectively), followed by fraction III (2.29 U/mg and 1.1-fold), fraction I (1.98 U/mg and 1.0 -fold), and fraction IV (1.78 U/mg and 0.9-fold). These results indicate that the purification of endoprotease from the CE was largely affected by the concentration of an ammonium sulfate, with the highest amount of activity observed in fractions containing lower concentrations of ammonium sulfate

Table 1. Endoprotease and exopeptidase activities of fractions obtained from the CE of cuttlefish Sepia officinalis hepatopancreas by the ammonium sulfate fractionation toward azocasein and LeuPNA as substrates

\begin{tabular}{lcccrrrr}
\hline Enzyme & Fraction $^{*}$ & $\begin{array}{c}\text { Total volume } \\
(\mathbf{m L})\end{array}$ & $\begin{array}{c}\text { Protein } \\
(\mathbf{m g} / \mathbf{m L})\end{array}$ & $\begin{array}{r}\text { Specific activity } \\
(\mathbf{U} / \mathbf{m g})\end{array}$ & $\begin{array}{c}\text { Total activity } \\
\text { (U) }\end{array}$ & $\begin{array}{c}\text { Recovery } \\
(\mathbf{\%})\end{array}$ & $\begin{array}{c}\text { Purification } \\
\text { (fold) }\end{array}$ \\
\hline Endoprotease & CE & 50.0 & 19.80 & 2.06 & $2,043.75$ & 100.0 & 1.0 \\
& I & 1.3 & 4.36 & 1.98 & 10.82 & 0.5 & 1.0 \\
& II & 3.8 & 10.71 & 2.86 & 115.03 & 5.6 & 1.4 \\
& III & $\mathbf{8 . 8}$ & $\mathbf{3 3 . 4 7}$ & $\mathbf{2 . 2 9}$ & $\mathbf{6 7 0 . 2 5}$ & $\mathbf{3 2 . 8}$ & $\mathbf{1 . 1}$ \\
& IV & 6.0 & 28.23 & 1.78 & 300.95 & 14.7 & 0.9 \\
& CE & 50.0 & 19.80 & 4.85 & $4,800.00$ & 100.0 & 1.0 \\
& I & 1.3 & 4.36 & 5.09 & 27.75 & 0.6 & 1.1 \\
& II & 3.8 & 10.71 & 3.68 & 147.75 & 3.1 & 0.8 \\
& III & $\mathbf{8 . 8}$ & $\mathbf{3 3 . 4 7}$ & $\mathbf{7 . 2 1}$ & $\mathbf{2 , 1 1 0 . 5 0}$ & $\mathbf{4 4 . 0}$ & $\mathbf{1 . 5}$ \\
& IV & 6.0 & 28.23 & 7.85 & $1,329.60$ & 27.7 & 1.6 \\
\hline
\end{tabular}

LeuPNA, L-leucine-p-nitroanilide.

${ }^{*} \mathrm{CE}$, crude extracts; I, 0-20\% saturated fraction; II, 20-40\% saturated fraction; III, 40-60\% saturated fraction; IV, $60-80 \%$ saturated fraction. 
(i.e., $0-20 \%$ and $20-40 \%$ ).

The total recovery of endoprotease activity was of $53.6 \%$ following fractionation of the CE by ASF. Recovery of endoprotease activity in fraction III was $32.8 \%$, which constituted $\sim 61 \%$ of the total recovery. Endoprotease activity in CE fractions was the highest in the fraction III (670.25 U), followed by the fraction IV (300.95 U), II (115.03 U), and I (10.82 U). These results indicate that the majority of endoprotease activity was contained in fraction III.

Bougatef et al. (2007) reported that endoprotease fractions, isolation from the CE of sardine Sardina pilchardus viscera had recovery and purify values of $40 \%$ and 1.12 -fold, respectively, in ASF fractions containing 0-30\% ammonium sulfate and $41.4 \%$ and 3.6 -fold, respectively, in the 30-60\% ammonium sulfate fraction. Bezerra et al. (2005) also reported the recovery and purification of endoprotease activity from Nile tilapia Oreochromis niloticus CE to be $1.1 \%$ and 2.45 -fold, respectively, for the $0-30 \%$ ammonium sulfate fraction and $34.7 \%$ and 6.78 -fold, respectively, for the $30-80 \%$ ammonium sulfate fraction. Furthermore, Kim et al. (2008) reported that the highest endoprotease activity was found in the 50-60\% ammonium sulfate fraction from Argentina shortfin squid CE. These studies suggest that endoprotease activity is highest in seafood CE fractions collected with high concentrations of ammonium sulfate.

Specific activity and purification of exopeptidase in fractions from cuttlefish HP CE were the highest in fraction IV (7.85 U/mg and 1.6-fold, respectively), followed by fraction III (7.21 U/mg and 1.5-fold), I (5.09 U/mg and 1.1-fold), and II $(3.68 \mathrm{U} / \mathrm{mg}$ and 0.8 -fold). According to these results, the purification of exoprotease was affected by the concentration of ammonium sulfate used during ASF fraction of cuttlefish HP CE.

Total recovery of exopeptidase activity from cuttlefish HP CE fractions was $75.4 \%$. The recovery of fraction III was $44.0 \%$ and that of fraction IV was $27.7 \%$, which together con- stituted $\sim 95 \%$ of the total recovery. Total exopeptidase activity was highest in fraction III $(2,110.50 \mathrm{U})$, followed by fraction IV (1,329.60 U), II (147.75 U), and I (27.75 U). These results indicate that fraction III contained the highest exoprotease activity and recovery. Indeed, Raksakulthai and Haard (1999) reported that purification and recovery of exopeptidase of from ASF fractionation of squid Illex illecebrosus HP CE was 2.84 -fold and $34.97 \%$, respectively, in fractions containing $20-80 \%$ ammonium sulfate. Chiou et al. (1988) also reported exopeptidase purification and recovery values from the CE fractions of the common gray mullet egg using 30-60\% ammonium sulfate to be 1.1 -fold and $75 \%$, respectively.

Fraction III showed both the highest total endoprotease activity value $(670.25 \mathrm{U})$ using an azocasein as a substrate and the highest exopeptidase value $(2,110.50 \mathrm{U})$ using LeuPNA as a substrate. The toal activity of exopeptidase in fraction III was 3.15 times higher than that of endoprotease. These results suggest that cuttlefish HP could be used as a potential source for the extraction of exopeptidase, which is an enzyme capable of catalyzing the cleavage of $\mathrm{N}$ - or $\mathrm{C}$-terminal amino acids in polypeptides, ASF appears to be an efficient method for the isolation of exopeptidase-active fraction from the $\mathrm{CE}$ of cuttlefish HP.

\section{Protease activity of PGF fraction}

Optimizing the conditions for fractionation of endoprotease and exopeptidase-activities from cuttlefish HP CE was performed using increasing concentrations of polyethylene glycol, Fractions were designated as fraction I ( $0-5 \%$ polyethylene glycol), II (5-10\% polyethylene glycol), III (10-20\% polyethylene glycol), and IV (20-40\% polyethylene glycol).

Table 2 shows endoprotease and exopeptidase activities, as well as the fractional yield obtained from the CE of cuttlefish HP using various concentrations of polyethylene glycol. Specific activity and endoprotease purification from the CE frac-

Table 2. Endoprotease and exopeptidase activities of fractions obtained from the CE of cuttlefish Sepia officinalis hepatopancreas by the polyethylene glycol fractionation toward azocasein and LeuPNA as substrates

\begin{tabular}{|c|c|c|c|c|c|c|c|}
\hline Enzyme & Fraction $^{*}$ & $\begin{array}{l}\text { Total volume } \\
(\mathrm{mL})\end{array}$ & $\begin{array}{c}\text { Protein } \\
(\mathrm{mg} / \mathrm{mL})\end{array}$ & $\begin{array}{c}\text { Specific activity } \\
\text { (U/mg) }\end{array}$ & $\begin{array}{c}\text { Total activity } \\
\text { (U) }\end{array}$ & $\begin{array}{c}\text { Recovery } \\
(\%)\end{array}$ & $\begin{array}{l}\text { Purification } \\
\text { (fold) }\end{array}$ \\
\hline \multirow[t]{5}{*}{ Endoprotease } & $\mathrm{CE}$ & 50.0 & 19.8 & 2.06 & $2,043.75$ & 100.0 & 1.0 \\
\hline & I & 7.5 & 12.78 & 2.67 & 255.50 & 12.5 & 1.3 \\
\hline & II & 10.0 & 18.77 & 1.64 & 307.31 & 15.0 & 0.8 \\
\hline & III & 4.0 & 27.28 & 2.44 & 266.34 & 13.0 & 1.2 \\
\hline & IV & 1.4 & 6.77 & 1.24 & 11.55 & 0.6 & 0.6 \\
\hline \multirow[t]{5}{*}{ Exopeptidase } & $\mathrm{CE}$ & 50.0 & 19.8 & 4.85 & $4,800.00$ & 100.0 & 1.0 \\
\hline & I & 7.5 & 12.78 & 5.16 & 495.00 & 10.3 & 1.1 \\
\hline & II & 10.0 & 18.77 & 2.74 & 514.00 & 10.7 & 0.6 \\
\hline & III & 4.0 & 27.28 & 14.71 & $1,605.60$ & 33.5 & 3.0 \\
\hline & IV & 1.4 & 6.77 & 8.57 & 80.04 & 1.7 & 1.8 \\
\hline
\end{tabular}

LeuPNA, L-leucine-p-nitroanilide.

${ }^{*} \mathrm{CE}$, crude extracts; I, 0-5\% fraction; II, 5-10\% fraction; III, 10-20\% fraction; IV, 20-40\% fraction. 
tions were highest in fraction I $(2.67 \mathrm{U} / \mathrm{mg}$ and 1.3 -fold, respectively), followed by fraction III (2.44 U/mg and 1.2-fold), II (1.64 U/mg and 0.8-fold), and IV (1.24 U/mg and 0.6-fold). According to these results, the purification of endoprotease from CE was largely affected by the concentration of polyethylene glycol, but the activity was independent of polyethylene glycol concentration.

The total recovery of endoprotease activity from the CE fractionation was $41.1 \%$, Individual fractions II, III, and I had endoprotease activity of $15.0 \%, 13.0 \%$, and $12.5 \%$, respectively, which corresponded respectively to $\sim 36.5 \%, 31.6 \%$, and $30.4 \%$ of the total activity recovered. Endoprotease activity was the highest in fraction II (370.31 U), followed by fraction III (266.34 U), I (255.50 U), and IV (11.55 U). These results indicate that endoprotease activity and recovery was highest in the fraction containing $5-10 \%$ polyetylene glycol, followed by the fraction containing $10-20 \%$ polyetylene glycol and that containing 0-5\% polyetylene glycol. Thus, endoprotease-active fraction could be isolated using $0-20 \%$ polyethylene glycol.

Specific activity and purification of exopeptidase from the $\mathrm{CE}$ fractions were the highest in the fraction III (14.71 U/mg and 3.0-fold, respectively), followed by fraction IV (8.57 U/ $\mathrm{mg}$ and 1.8-fold), I (5.16 U/mg and 1.1-fold), and II (2.74 U/ $\mathrm{mg}$ and 0.6 -fold). These results suggest that the purification of exopeptidase from the $\mathrm{CE}$ was influenced by concentration of polyethylene glycol, with higher concentration $(>10 \%)$ yielding higher activities and purities.

Total recovery of exopeptidase from CE fractions of cuttlefish HP was $56.2 \%$. The recovery of exopeptidase activity in fraction III was $33.5 \%$, which constituted $\sim 60 \%$ of the total recovery. Total exopeptidase activity was the highest in fraction III (1,605.60 U), followed by fraction II (514.00 U), I (495.00 $\mathrm{U})$, and IV (80.04 U). These results indicate exoprotease activity is highest in fraction III, suggesting exoprotease activity could be effectively fractionated using $10-20 \%$ polyethylene glycol. The highest total endoprotease activity (307.31 U) was observed in fraction II, with the highest exopeptidase activ-

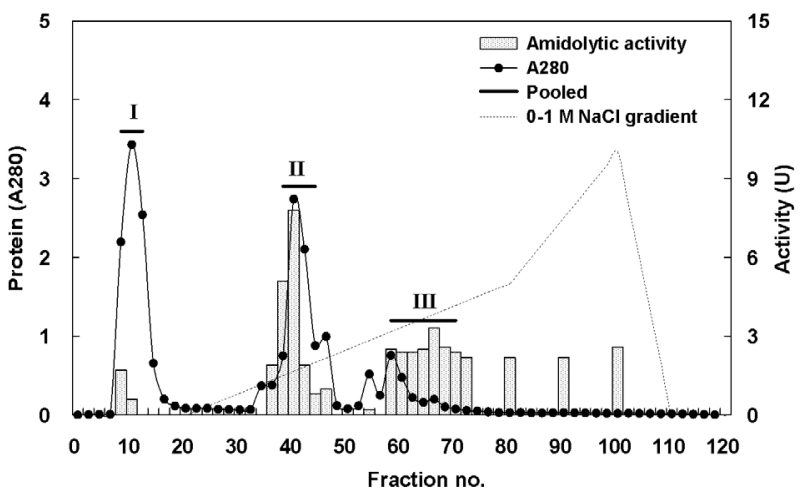

Fig. 1. DEAE-650M ion exchange chromatogram of fractions from the crude extracts of cuttlefish Sepia officinalis hepatopancreas. I, concentrates of fraction no. 8-12; II, concentrates of fraction no. 38-44; III, concentrates of fraction no. 58-70.

ity $(1,605.60 \mathrm{U})$ present in fraction III. The total activity of exopeptidase in fraction III was 5.22 times higher than that of endoprotease in fraction II. These results suggest that cuttlefish HP could be used as a potential source for the extraction of exopeptidase and that PGF is an efficient method for isolating exopeptidase-active fractions from the $\mathrm{CE}$ of cuttlefish HP.

\section{Protease activity of IEC fractions}

Fig. 1 shows a chromatogram of the optimized IEG conditions used to isolate endoprotease- and exopeptidase-active fractions from cuttlefish HP using a DEAE-650M ion exchange resin. Based on the protein concentration and enzymatic activities of endoprotease and exopeptidase, fractions were pooled, concentrated, and designated as fraction I (concentrates of fraction 8-12), II (concentrates of fraction 38-44), and III (concentrates of fraction 58-70).

Endoprotease and exopeptidase activities, as well as the fractional CE yield of cuttlefish HP separated by IEC, are shown in Table 3. Specific activity and endoprotease purity was highest in fraction III $(26.31 \mathrm{U} / \mathrm{mg}$ and 12.7 -fold, respec-

Table 3. Endoprotease and exopeptidase activities of fractions obtained from the CE of cuttlefish Sepia officinalis hepatopancreas by the DEAE-650M ion exchange chromatography toward azocasein and LeuPNA as substrates

\begin{tabular}{lccccrrr}
\hline Enzyme & Fraction $^{*}$ & $\begin{array}{c}\text { Total volume } \\
(\mathbf{m L})\end{array}$ & $\begin{array}{c}\text { Protein } \\
(\mathbf{m g} / \mathbf{m L})\end{array}$ & $\begin{array}{c}\text { Specific activity } \\
(\mathbf{U} / \mathbf{m g})\end{array}$ & $\begin{array}{c}\text { Total activity } \\
\text { (U) }\end{array}$ & $\begin{array}{c}\text { Recovery } \\
(\mathbf{\%})\end{array}$ & $\begin{array}{c}\text { Purification } \\
(\mathbf{f o l d})\end{array}$ \\
\hline Endoprotease & CE & 50.0 & 19.80 & 2.06 & $2,043.75$ & 100.0 & 1.0 \\
& I & $\mathbf{1 7 . 6}$ & $\mathbf{4 . 7 5}$ & $\mathbf{5 . 2 3}$ & $\mathbf{4 3 6 . 8 9}$ & $\mathbf{2 1 . 4}$ & $\mathbf{2 . 5}$ \\
& II & 19.8 & 8.14 & 1.97 & 317.68 & 15.5 & 1.0 \\
Exopeptidase & III & 62.7 & 0.19 & 26.31 & 313.40 & 15.3 & 12.7 \\
& CE & 50.0 & 19.80 & 4.85 & $4,800.00$ & 100.0 & 1.0 \\
& I & 17.6 & 4.75 & 5.54 & 463.54 & 9.7 & 1.1 \\
& II & $\mathbf{1 9 . 8}$ & $\mathbf{8 . 1 4}$ & $\mathbf{7 . 4 2}$ & $\mathbf{1 . 1 9 6 . 2 2}$ & $\mathbf{2 4 . 9}$ & $\mathbf{1 . 5}$ \\
& III & 62.7 & 0.19 & 11.32 & 134.81 & 2.8 & 2.3 \\
\hline
\end{tabular}

LeuPNA, L-leucine- $p$-nitroanilide.

"CE, crude extracts; I, concentrates of fraction no. 8-12; II, concentrates of fraction no. 38-44; III, concentrates of fraction no. 58-70. 
tively), followed by fraction I (5.23 U/mg and 2.5-fold) and II (1.97 U/mg and 1.0-fold). According to the results, the purification of endoprotease from the CE was largely affected by the ionic strength of the resin. These results indicate that IEC is an efficient method for obtaining endoprotease-active fraction from the CE of cuttlefish HP.

Total recovery of endoprotease from CE fractions of the cuttlefish HP was $52.2 \%$, Among the three pooled fractions, endoprotease recoveries for fraction I and II were $21.4 \%$ and $15.5 \%$, respectively, which constituted approximately $41.0 \%$ and $29.7 \%$, respectively, of the total recovery. Total activity of endoprotease in the CE fractions was the highest in fraction I (436.89 U), followed by fraction II (317.68 U) and III (313.40 $\mathrm{U})$. These results show the highest endoprotease activity in fraction I, which indicates that endoprotease-active fractions can be isolated by IEC using a DEAE-650M ion exchange resin.

Fu et al. (2005) reported that an alkaline protease-active fraction from the CE of sea cucumber Stichopus japonicus could be fractionated by IEC with a recovery and purity of $7.8 \%$ and 1.29 -fold, respectively. Hernández-Cortés et al. (1997) also reported that a protease-active fraction from the CE of shrimp Penaeus vannamei HP could be isolated by IEC, yielding a recovery and purity of $50 \%$ and 10 -fold, respectively.

Specific activity and purification of exopeptidase from CE fractions, of cuttlefish HP were the highest in fraction III (11.32 U/mg and 2.3-fold, respectively), followed by fraction II (7.42 U/mg and 1.5-fold), and I (5.54 U/mg and 1.1-fold). These findings suggested that IEC may be an efficient method for obtaining exoprotease-active fractions from the $\mathrm{CE}$ of cuttlefish HP.

Total recovery of exopeptidase in CE fractions was $37.4 \%$, with the individual recovery of fraction II being $24.9 \%$, which constituted $\sim 66.6 \%$ of the total recovery. Exopeptidase activity was highest in fraction II $(1,196.22 \mathrm{U})$, followed by fraction I (463.54 U) and III (134.81 U). These results show exopeptidase to be active and present in high amounts in fraction II. Thus, the exopeptidase-active fraction could be effectively isolated from the CE using IEC.

Vo et al. (1983) reported that a protease-active fraction from the $\mathrm{CE}$ of sardine viscera could be isolated by IEC, with a recovery and purity of $79 \%$ and 36 -fold, respectively. Umetsu et al. (2003) also reported that a protease-active fraction from the CE of scallop Patinopecten yessoensis midgut gland could be isolated by IEC, with a recovery and purification of $46.7 \%$ and 16-fold, respectively.

Total activity was highest in fraction I (436.89 U) for endoprotease and in fraction II $(1,196.22 \mathrm{U})$ for exopeptidase. The total activity of exopeptidase was 2.74 times higher than that of endoprotease. These results suggest that cuttlefish HP may be a potential source the extraction of exopeptidase, and DEAE-650M is an efficient resin for isolating exopeptidaseactive fractions from the CE of cuttlefish HP using IEC.

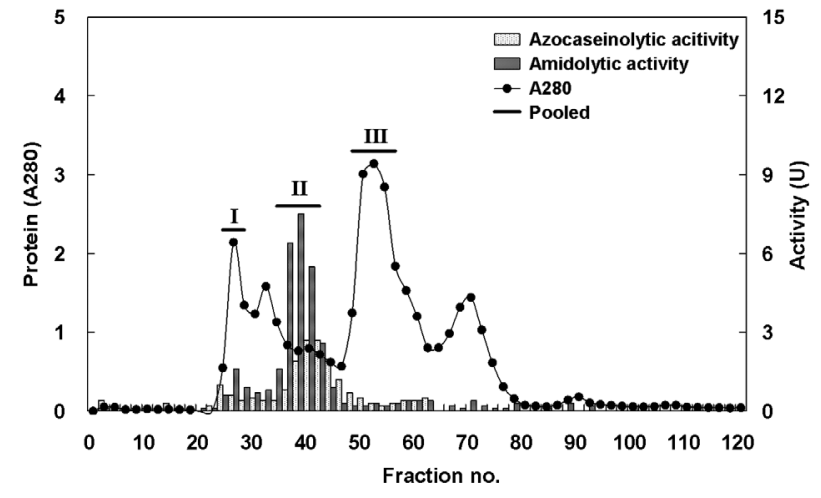

Fig. 2. Sephacryl S-300 gel filtration chromatogram of fractions from the crude extracts of cuttlefish Sepia officinalis hepatopancreas. I, concentrates of fraction no. 24-28; II, concentrates of fraction no. 34-42; III, concentrates of fraction no. 48-56.

\section{Protease activity of fractions obtained by GFC}

Fig. 2 shows the optimized isolation of endoprotease- and exopeptidase-active fractions from the $\mathrm{CE}$ of cuttlefish HP by GFC using a Sephacryl S-300 resin. Based on the chromatogram, endoprotease and exopeptidase, activity levels and protein concentration values, fractions were designated as fraction I (concentrate of fractions 24-28), II (concentrate of fractions 38-42), and III (concentrate of fractions 48-56).

Endoprotease and exopeptidase activities, as well as the fractional yield from the CE of cuttlefish HP isolated by GFC are shown in Table 4. Specific activity and endoprotease purity are highest in fraction III $(6.46 \mathrm{U} / \mathrm{mg}$ and 3.1 -fold, respectively), followed by fraction II ( $3.58 \mathrm{U} / \mathrm{mg}$ and 1.7 -fold) and $\mathrm{I}(0.65 \mathrm{U} / \mathrm{mg}$ and 0.3 -fold). According to these results, the purification of endoprotease from the $\mathrm{CE}$ was significantly affected by difference in molecular weight. These results suggest that GFC is an efficient method for the separation of endoprotease-active fractions from the CE of cuttlefish HP.

Total recovery of endoprotease from GFC fractions was $52.3 \%$. Among the three fractions, recovery of endoprotease in fraction II was $41.2 \%$, which constituted $\sim 78.8 \%$ of the total recovery. Total activity of endoprotease in the GFC fractions was highest in fraction II $(842.60 \mathrm{U})$, followed by fraction III $(177.78 \mathrm{U})$ and I (49.23 U). The total endoprotease activity and recovery results showed the highest value in fraction II. Thus, endoprotease-active fractions could be effectively isolated using Sephacryl S-300 resin.

Kishimura et al. (2005) reported that a protease-active fraction from the CE of anchovy Engraulis japonica viscera could be fractionated with Sephacryl S-200 gel chromatography, to yield a $66 \%$ recovery and 12 -fold purity. Specific activity and purification of exopeptidase by GFC was highest in fraction II (11.48 U/mg and 2.4-fold, respectively), followed by fraction I (6.39 U/mg and 1.3-fold). These results suggested that GFC may be an efficient method for obtaining exopeptidase-active fractions from the CE of cuttlefish HP. 
Total recovery of exopeptidase by GFC fractionation was $66.4 \%$. Recovery of exopeptidase in fraction II was $56.3 \%$, which constituted $\sim 81.2 \%$ of the total recovery. Total exopeptidase activity was highest in the fraction II (2,704.70 U), followed by fraction I ( $480.74 \mathrm{U})$. These results indicate the total activity and recovery of exopeptidase of fractions was highest in fraction II. Thus, the exopeptidase-active fraction could be effectively isolated by GFC using a Sephacryl S-300 resin.

Total activity was highest for both endoprotease (842.60 $\mathrm{U})$ and exoprotease $(2,704.70 \mathrm{U})$ in fraction II, with the total activity of exopeptidase being 3.21 times higher than that of endoprotease in this fraction. These results suggest that cuttlefish HP could be used as a potential source for the extraction of exopeptidase and that GFC fractionation using a Sephacryl $\mathrm{S}-300$ resin is an efficient method for the isolation of exopeptidase-active fractions from the CE of cuttlefish HP.

\section{Comparison of the highest fractions in total activity of enzyme among fractions obtained by various fractionation methods}

Fraction III of ASF contained the highest total activity for both azocasein and LeuPNA, while fraction II and III collected by PGF had the highest activity for the respective substrates. Fraction I and II of IEC had the highest azocasein and LeuPNA total activity, respectively, while the highest activities for GFC were both found in fraction II. Endoprotease and exopeptidase activities, as well as fractional yield, are shown in Table 5 for each of the fractionation methods. Specific activity and endoprotease purification were the highest in fraction I (5.23 U/mg and 2.5-fold, respectively) of IEC, followed by fraction II (3.58 U/mg and 1.7-fold) of GFC, fraction III (2.29 $\mathrm{U} / \mathrm{mg}$ and 1.1-fold) of ASF, and fraction II (1.64 U/mg and

Table 4. Endoprotease and exopeptidase activities of fractions obtained from the CE of cuttlefish Sepia officinalis hepatopancreas by the Sephacryl S-300 gel filtration chromatography toward azocasein and LeuPNA as substrates

\begin{tabular}{|c|c|c|c|c|c|c|c|}
\hline Enzyme & Fraction $^{*}$ & $\begin{array}{c}\text { Total volume } \\
(\mathrm{mL})\end{array}$ & $\begin{array}{c}\text { Protein } \\
(\mathrm{mg} / \mathrm{mL})\end{array}$ & $\begin{array}{c}\text { Specific activity } \\
\text { (U/mg) }\end{array}$ & $\begin{array}{c}\text { Total activity } \\
\text { (U) }\end{array}$ & $\begin{array}{c}\text { Recovery } \\
(\%)\end{array}$ & $\begin{array}{c}\text { Purification } \\
\text { (fold) }\end{array}$ \\
\hline \multirow[t]{4}{*}{ Endoprotease } & $\mathrm{CE}$ & 50.0 & 19.80 & 2.06 & $2,043.75$ & 100.0 & 1.0 \\
\hline & I & 43.0 & 1.75 & 0.65 & 49.23 & 2.4 & 0.3 \\
\hline & II & 40.0 & 5.89 & 3.58 & 842.60 & 41.2 & 1.7 \\
\hline & III & 22.0 & 1.25 & 6.46 & 177.78 & 8.7 & 3.1 \\
\hline \multirow[t]{4}{*}{ Exopeptidase } & $\mathrm{CE}$ & 50.0 & 19.80 & 4.85 & $4,800.00$ & 100.0 & 1.0 \\
\hline & I & 43.0 & 1.75 & 6.39 & 480.74 & 10.0 & 1.3 \\
\hline & II & 40.0 & 5.89 & 11.48 & $2,704.70$ & 56.3 & 2.4 \\
\hline & III & 22.0 & 1.25 & 0.17 & 4.73 & 0.1 & 0.0 \\
\hline
\end{tabular}

LeuPNA, L-leucine-p-nitroanilide.

"CE, crude extracts: I, concentrates of fraction no. 24-28; II, concentrates of fraction no. 34-42; III, concentrates of fraction no. 48-56.

Table 5. Comparison of enzyme activities of fractions from the CE of cuttlefish Sepia officinalis hepatopancreas obtained by different fractionation methods toward azocasein and LeuPNA as substrates

\begin{tabular}{|c|c|c|c|c|c|c|c|c|}
\hline Enzyme & Fractionation method & Fraction $^{*}$ & $\begin{array}{l}\text { Total volume } \\
\text { (mL) }\end{array}$ & $\begin{array}{l}\text { Protein } \\
(\mathrm{mg} / \mathrm{mL})\end{array}$ & $\begin{array}{l}\text { Specific } \\
\text { activity } \\
\text { (U/mg) }\end{array}$ & $\begin{array}{c}\text { Total activity } \\
(\mathbf{U})^{\dagger}\end{array}$ & $\begin{array}{l}\text { Recovery } \\
(\%)\end{array}$ & $\begin{array}{l}\text { Purification } \\
\text { (fold) }\end{array}$ \\
\hline \multirow[t]{5}{*}{ Endoprotease } & Crude extracts & $\mathrm{CE}$ & 50.0 & 19.80 & 2.06 & $2,043.75$ & 100.0 & 1.0 \\
\hline & Ammonium sulfate & III & 8.8 & 33.47 & 2.29 & 670.25 & 32.8 & 1.1 \\
\hline & Polyethylene glycol & II & 10.0 & 18.77 & 1.64 & 307.31 & 15.0 & 0.8 \\
\hline & $\begin{array}{l}\text { Ion exchange } \\
\text { chromatography }\end{array}$ & I & 17.6 & 4.75 & 5.23 & 436.89 & 21.4 & 2.5 \\
\hline & $\begin{array}{l}\text { Gel filtration } \\
\text { chromatography }\end{array}$ & II & 40.0 & 5.89 & 3.58 & 842.60 & 41.2 & 1.7 \\
\hline \multirow[t]{5}{*}{ Exopeptidase } & Crude extracts & $\mathrm{CE}$ & 50.0 & 19.80 & 4.85 & $4,800.00$ & 100.0 & 1.0 \\
\hline & Ammonium sulfate & III & 8.8 & 33.47 & 7.21 & $2,110.50$ & 44.0 & 1.5 \\
\hline & Polyethylene glycol & III & 4.0 & 27.28 & 14.71 & $1,605.60$ & 33.5 & 3.0 \\
\hline & $\begin{array}{l}\text { Ion exchange } \\
\text { chromatography }\end{array}$ & II & 19.8 & 8.14 & 7.42 & $1,196.22$ & 24.9 & 1.5 \\
\hline & $\begin{array}{l}\text { Gel filtration } \\
\text { chromatography }\end{array}$ & II & 40.0 & 5.89 & 11.48 & $2,704.70$ & 56.3 & 2.4 \\
\hline
\end{tabular}

LeuPNA, L-leucine-p-nitroanilide.

*Fraction III of ammonium sulfate fractionation, 40-60\% saturated fraction; Fraction III of polyethylene glycol fractionation, 10-20\% fraction; Fraction I and II of ion exchange chromatography, concentrates of fraction no. 8-12 and fraction no. 38-44, respectively; Fraction II of gel filtration chromatography, concentrates of fraction no. 34-42.

${ }^{\dagger}$ Total activities $(\mathrm{U})$ were calculated based on the $50 \mathrm{~mL}$ of the crude extracts (CE). 
0.8 -fold) of PGF. Total endoprotease activity was the highest in the fraction II (842.60 U) of GFC, followed by fraction III (670.25 U) of ASF, fraction I (436.89 U) of IEC, and fraction II (307.31 U) of PGF. These results suggest that GFC is the most efficient method for separating endoprotease-active fraction from the CE of cuttlefish HP.

Specific activity and purification of exopeptidase were the highest in fraction III (14.71 U/mg and 3.0-fold, respectively) of PGF, followed by fraction II (11.48 U/mg and 2.3-fold) of GFC, fraction II (7.42 U/mg and 1.5-fold) of IEC, and fraction III (7.21 U/mg and 1.5-fold) of ASF. Total activity toward exopeptidase was highest in fraction II (2,704.70 U) of GFC, followed by fraction III $(2,110.50 \mathrm{U})$ of ASF, fraction III $(1,605.60 \mathrm{U})$ of PGF, and fraction II $(1,196.22 \mathrm{U})$ of IEC.

Total activity results suggest that GFC is the most efficient method for separating exopeptidase-active fractions from the CE of cuttlefish HP. Fraction II of GFC, which had the highest total activity toward both exopeptidase and endoprotease, had 3.21 times higher total activity toward exopeptidase than endoprotease. These results suggest that cuttlefish HP could be used as a potential source for extracting exopeptidase, with GFC being the most efficient method studied here for separating exopeptidase-active fractions from the $\mathrm{CE}$ of cuttlefish HP.

\section{Acknowledgments}

This research was suppoted by Basic Science Research Program through the National Research Foundation of Korea (NRF) funded by the Ministry of Education, Science and Technology (2010-0021825).

\section{References}

Aewsiri T, Benjakul S and Visessanguan W. 2009. Functional properties of gelatin from cuttlefish (Sepia pharaonis) skin as affected by bleaching using hydrogen peroxide. Food Chem 115, 243-249.

Agriculture and Fishery Statistics Department. 2010. Statistical Report of Fish Catches. Statistics Korea, Seoul, KR.

Bezerra RS, Lins EJF, Alencar RB, Paiva PMG, Chaves MEC, Coelho LCBB and Carvalho LB Jr. 2005. Alkaline proteinase from intenstine of Nile tilapia (Oreochromis niloticus). Process Biochem 40, 1829-1834.

Bougatef A, Souissi N, Fakhfakh N, Ellouz-Triki Y and Nasri M. 2007. Purification and characterization of trypsin from the viscera of sardine (Sardina pilchardus). Food Chem 102, 343-350.

Bumberger E and Belitz HD. 1993. Bitter taste of enzymatic hydrolysates of casein. Z Lebensm Unters Forsch 197, 14-19.

Chiou TK, Matsui T and Konosu S. 1988. Purification and properties of an aminopeptidase from mullet, Mugil cephalus, roe. Agric Biol Chem 52, 235-242.

Clegg KM, Lim CL and Manson W. 1974. The structure of a bitter peptide derived from casein by digestion with papain. J Dairy Res 41,
283-287.

Dawson RMC, Elliott DC, Elliott WH and Jones KM. 1986. Data for Biochemical Research. 3rd ed. Oxford University Press, Oxford, GB, pp. 417-441.

Deejing S, Yoshimune K, Lumyong S and Moriguchi M. 2005. Purification and characterization of hyperthermotolerant leucine aminopeptidase from Geobacillus thermoleovorans 47b. J Ind Microbiol Biotechnol 32, 269-276.

Fu XY, Xue CH, Miao BC, Li ZJ, Yang WG and Wang DF. 2005. Study of a highly alkaline protease extracted from digestive tract of sea cucumber (Stichopus japonicus). Food Res Int 38, 323-329.

García-Carreño FL and Haard NF. 1993. Characterization of proteinase classes in langostilla (Pleuroncodes planipes) and crayfish (Pacifastacus astacus) extracts. J Food Biochem 17, 97-113.

Gupta R, Beg QK and Lorenz P. 2002. Bacterial alkaline proteases: molecular approaches and industrial applications. Appl Microbiol Biotechnol 59, 15-32.

Haard NF. 1990. Enzymes from food myosystems. J Muscle Foods 1, 293-338.

Hernández-Cortés P, Whitaker JR and García-Carreño FL. 1997. Purification and characterization of chymotrypsin from Penaeus vannamei (Crustacea: Decapoda). J Food Biochem 21, 497-514.

Heu MS, Kim JS, Shahidi F, Jeong Y and Jeon YJ. 2003. Extraction, fractionation and activity characteristics of proteases from shrimp processing discards. J Food Biochem 27, 221-236.

Hoque MS, Benjakul S and Prodpran T. 2010. Effect of heat treatment of film-forming solution on the properties of film from cuttlefish (Sepia pharaonis) skin gelatin. J Food Eng 96, 66-73.

Ivankovic H, Gallego Ferrer G, Tkalcec E, Orlic S and Ivankovic M. 2009. Preparation of highly porous hydroxyapatite from cuttlefish bone. J Mater Sci Mater Med 20, 1039-1046.

Izawa N, Tokuyasu K and Hayashi K. 1997. Debittering of protein hydrolysates using Aeromonas caviae aminopeptidase. J Agric Food Chem 45, 543-545.

Kechaou ES, Dumay J, Donnay-Moreno C, Jaouen P, Gouygou JP, Berge JP and Amar RB. 2009. Enzymatic hydrolysis of cuttlefish (Sepia officinalis) and sardine (Sardina pilchardus) viscera using commercial proteases: effects on lipid distribution and amino composition. J Biosci Bioeng 107, 158-164.

Kim HS, Kim JS and Heu MS. 2008. Fractionation of endoprotease from viscera of the argentina shortfin squid Illex argentinus. J Korean Fish Soc 41, 176-181.

Kishimura H, Hayashi K, Miyashita Y and Nonami Y. 2005. Characteristics of two trypsin isozymes from the viscera of Japanese anchovy (Engraulis japonica). J Food Biochem 29, 459-469.

Lowry OH, Rosebrough NJ, Farr AL and Randall RJ. 1951. Protein measurement with the folin phenol reagent. J Biol Chem 193, 265-275.

Matoba T, Hayashi R and Hata T. 1970. Isolation of bitter peptides from tryptic hydrolysate of casein and their chemical structure. Agric Biol Chem 34, 1235-1243.

Minagawa E, Kaminogawa S, Tsukasaki F and Yamauchi K. 1989. Debittering mechanism in bitter peptides of enzymatic hydrolysates from milk casein by aminopeptidase T. J Food Sci 54, 12251229. 
Nagai T, Yamashita E, Taniguchi K, Kanamori N and Suzuki N. 2001. Isolation and characterisation of collagen from the outer skin waste material of cuttlefish (Sepia lycidas). Food Chem 72, 425-429.

Park JH, Lee H, Lee GY, Kim HR, Kim YW and Lee YB. 2011. Development of refined cuttlefish (Todarodes pacificus) oil and its use as functional ingredients. Food Sci Biotechnol 20, 389-394.

Raksakulthai R and Haard NF. 1999. Purification and characterization of aminopeptidase fractions from squid (Illex illecebrosus) hepatopancreas. J Food Biochem 23, 123-144.

Rao MB, Tanksale AM, Ghatge MS and Deshpande VV. 1998. Molecular and biotechnological aspects of microbial proteases. Microbiol Mol Biol Rev 62, 597-635.

Souissi N, Ellouz-Triki Y, Bougatef A, Blibech M and Nasri M. 2008. Preparation and use of media for protease-producing bacterial strains based on by-products from cuttlefish (Sepia officinalis) and wastewaters from marine-products processing factories. Microbiol Res 163, 473-480.

Starky PM. 1977. Elastase and cathepsin G: the serine proteinases of human neutrophil leucocytes and spleen. In: Proteinases in Mammalian Cells and Tissues. Barrett AJ, ed. North-Holland Publishing Co., Amsterdam, NL, pp. 57-89.

Umetsu H, Arai M, Ota T, Kudo R, Sugiura H, Ishiyama H and Sasaki K. 2003. Purification and properties of an aminopeptidase from the mid-gut gland of scallop (Patinopecten yessoensis). Comp Biochem Physiol B Biochem Mol Biol 136, 935-942.

Vo VT, Kusakabe I and Murakami K. 1983. Purification and some properties of two aminopeptidases from sardines. Agric Biol Chem 47, 2453-2459. 